used in photogrammetry. Research on the techniques of measuring high-intensity gamma-ray sources continued and also on the friction of ice.

The Division of Pure Physics continued to study the behaviour of cosmic rays as they penetrate matter, and measurements taken in 1954 and 1955 in two cruises, one to the Arctic and the other to the Antarctic, have now shown that the Earth's magnetic field as it affects cosmic rays differs considerably from that derived from surface geomagnetic measurements. Completion of work on the lowtemperature electrical and thermal conductivity of the alkali metals indicates that the fundamental theory is seriously inadequate and for thermal conductivity a new semi-theoretical expression has been derived which accounts well for data over a wide range of match. Investigation of the spectra of polyatomic free radicals produced by the flash method of photodecomposition continued and the rotational Raman spectra of benzene, allene, cyanogen, butatriene, diacetylene and dimethylacetylene have been photographed under high resolution and their moments of inertia determined. Some work has been completed on a rigorous treatment of the central fieldindependent-particle nuclear shell model on the basis of the variational principle, and crystal structure studies made of the isomorphous dihydrate of lithium, sodium and silver dithionates, of acridiene II and of some aliphatic dibasic acids and their potassium salts.

The Division of Medical Research in 1955 awarded 145 grants-in-aid of research, in addition to seven consolidated grants, totalling 652,056 dollars, and of these, thirty-one grants were for cardiovascular research, to which a proportion of certain consolidated grants is also devoted. A Canadian Heart Foundation is now to be established, and the Council, on the recommendation of the Advisory Committee on Medical Research, is creating a new category of medical research associate, six of whom were expected to be appointed in 1956 .

The Division of Building Research opened a small Atlantic Regional Station in Halifax during the year and the Prairie Regional Station at Saskatoon concentrated with laboratory studies of cold-weather building problems. The Fire Research Section continued its studies of major fires in the Ottawa area, field studies of housing problems were made in many parts of the country, regional soil temperature observations were further extended and the effects of frost were studied in connexion with the whole problem of winter construction. Much of the work of the Division of Mechanical Engineering continues to be related to defence, but that for industry is increasing. An investigation of the icing of helicopters was undertaken for the Royal Canadian Navy and instruments designed and constructed during the year have included a flame detector for use with gas turbines in flight or on the ground, devices and techniques for investigating 'howling' combustion, a wave profile recorder, preliminary designs for air-speed measuring devices for navigating helicopters and control systems for a pilot supersonic tunnel, a wave-making machine, and a shipmodel profiling machine.

About half the work of the Radio and Electrical Engineering Division is on defence projects. In preparation for the International Geophysical Year an automatic radar system was designed for recording the aurora and the prototype tested continuously for eight rnonths. Studies are being made of the fundamental electrical and optical properties of dielectric crystals, and a Czochralski-type furnace has been built to produce the superpure silicon single crystals needed for a study of silicon transistors. Fundamental antenna studies included development of a new type of two-dimensional slotted wave-guide array, the use of ferrites at microwave frequencies, and the performance of a slot in a dielectric-coated cylinder. A merchant marine radar of exceptionally good short-range definition and long-range performance has been developed and constructed, but the microwave position-fixing system developed for inshore survey use required certain modifications. An electrical thermometer has been designed which provides continuous indication of the temperature in freshwater lakes at various depths, and an investigation of the explosion hazard of static electricity generated by grain handling is almost complete. A radio survey in Banff and Yoho National Parks indicated that a system operating in the 152-174 Mc./s. band and consisting of two base stations and one automatic repeater station would provide communication cover to most of the warden stations and continuous coverage along the Trans-Canada Highway. The cardiac defibrillator-stimulator and electronic device developed for resuscitation of the heart from fibrillation is now being manufactured under licence and development of blood pressure measuring equipment for inclusion in the resuscitator continues.

\section{INDUSTRIAL ACCIDENTS}

$T$ HE annual report of the Chief Inspector of Factories for $1955^{*}$ records the lowest accidentrate yet achieved, although the number of accidents, 188,403 , was 1.2 per cent greater than in 1954 , the factory population being $2 \cdot 5$ per cent higher and the number of factories with power 0.4 per cent greater than in 1954. Since 1953 the accident-rate for women has increased, and the Chief Inspector attributes this largely to the general rise in the number of women employed, of whom many are new to industry. $\mathrm{He}$ stresses the responsibility of management for special care to protect those entering industry for the first time and completely unfamiliar with their environment, as well as the importance of proper induction, training and supervision for young persons.

A separate chapter of the report reviews the changes in the rubber industry since 1922 in relation to the Indiarubber Regulations, 1955, prohibiting the use of carbon disulphide in the cold-cure process of vulcanizing in proofing cloth with rubber, which came into force during the year, and the Chief Inspector comments at greater length than usual on factory medical and nursing services. An outstanding feature of the year was the inception of a survey of conditions affecting health in all factories in Halifax, and of another survey of such conditions in the pottery industry. Another feature was the increased attention given to factory design. The Midland Regional Board for Industry sponsored some research into relative costs and merits of various types of factory premises, including the methods and costs of construction and the effect of the different types on production.

The increase in mechanization throughout industry generally is eliminating much heavy manual and

- Annual Report of the Chief Inspector of Factories for the year 1955. Pp. 275. (Cmd. 8.) (London: H.M. Stationery Office, 1956.) 1955. net. 
dirty work formerly undertaken in factories, but the new methods of production often bring new hazards in more complicated form. Even where full automation would scarcely be worth while, firms are giving serious thought to some degree of electronic control, but the limit placed on automation by the need to extend and improve the training of the necessary technicians is generally recognized. The development of automatic control equipment will tend to increase safety in the heavier industries, but the Chief Inspector points out that it may be necessary, in the interest of safety, to give much more thought to electrical circuitry and programming. The use of electronic computers to extend our basic scientific knowledge in many industrial applications, such as fluid flow, heat transfer and electrical transients, and to solve problems in these fields, also bears on the improvement of industrial safety. The greatest single cause of accidents on electric supply systems remains the misconduct of work involving the handling of, or approach to, conductors, especially high-voltage conductors.

The control of nuclear reactors places a heavy responsibility on the engineer for the design and maintenance of reliable equipment to supervise critical and dangerous fission processes. The uses of ionizing radiations in industry are now well established, and, besides the Conference at Geneva on the Peaceful Uses of Atomic Energy, the outstanding events of the year in this respect were the publication in May of the revised "Recommendations of the International Commission on Radiological Protection" and the transfer, at the end of the year, of the radiation film badge service from the National Physical Laboratory to the Radiological Protection Service run jointly by the Ministry of Health and the Medical Research Council.

The Chief Inspector believes that the cumulative effect on production and working conditions of a number of changes in mechanization and automatic control in relatively small items is probably much greater than that of the more obviously impressive examples of full automation in the larger plants, and he reiterates that accident prevention schemes, however excellent on paper, are doomed to stagnation and ultimate failure without a genuine and continuing interest by management at the highest level.

\section{THE INTERNATIONAL CIVIL AVIATION ORGANIZATION STANDARD ATMOSPHERE}

$I_{\mathrm{N}}^{\mathrm{S}}$ 1924 the International Commission for Air Navigation devised a standard atmosphere $\theta^{1}$ to be used in the graduation of aircraft pressure altimeters to give approximate readings of height and for the comparison of aircraft performances such as attempts at height and speed records necessarily made in different atmospheric conditions. This standard atmosphere approximated, probably deliberately, to mean conditions over western Europe. The specification, briefly, was: acceleration of gravity, $980.62 \mathrm{~cm} . / \mathrm{sec}^{2}$ at all heights; pressure at zero height, $1,013 \cdot 25 \mathrm{mb}$; temperature at zero height, $288^{\circ} \mathrm{K}$. ; lapse rate of temperature, $6 \cdot 5^{\circ} \mathrm{C}$. I $\mathrm{km}$. to $11 \mathrm{~km}$., and zero above. Graduation with this atmosphere gave, in general, much more accurate height readings on aircraft altimeters than the previously used assumption of temperature $50^{\circ} \mathrm{F}$. at all heights. No upper limit to the standard atmosphere was prescribed in the specification, but this was of little importance because it was many years after 1924 before aircraft reached heights at which its specification was quite unrealistic. In 1954 the International Civil Aviation Organization revised the International Commission for Air Navigation standard $^{2}$ slightly by specifying height in terms of geopotential units. The geopotential height $H$ in c.g.s. units at geometric height $z$ is given by

$$
\frac{1}{980 \cdot 665} \int_{0}^{z} g \mathrm{~d} z
$$

More important than this, the Organization recognized that the standard atmosphere could be used as a suitable standard reference for the upper air, except as regards water vapour, up to an altitude of about $20 \mathrm{~km}$. in temperate latitudes. The extension of the standard atmosphere above $20 \mathrm{~km}$. as an approximation to average conditions at those altitudes must, it was stated, await the collection and analysis of a considerable number of reliable upper air soundings.

A committee of representatives of a number of United States organizations, including the Air Force Air Research and Development Command, the Air Force Geophysics Research Directorate, the Ballistics Research Laboratory, the National Advisory Committee for Aeronautics, the National Bureau of Standards, the Naval Research Laboratory and the Weather Bureau, has now decided on representation of the atmosphere up to $300 \mathrm{~km}$. The data up to about $32 \mathrm{~km}$. appear to have been obtained from radio-sonde observations and presumably at higher levels from a combination of measurements by rocket-borne instruments, and inferences from the luminescence of meteors, transmission of sound to great distances and atmospheric tides. The Committee, the address of which is Geophysics Research Directorate, 415 Summer Street, Boston 10, Massachusetts, U.S.A., had recently distributed a sum. mary of tne extension in tabular and diagrammatic forms.

The extension links with the International Civil Aviation Organization atmosphere at the foot and has the constant temperature, $216 \cdot 6^{\circ} \mathrm{K}$., of the International Civil Aviation Organization lower 'stratosphere' to $25 \mathrm{~km}$. 'Then comes the rise of temperature with height associated with the ozone layer, giving a temperature between 47 and $53 \mathrm{~km}$. of $282 \cdot 66^{\circ} \mathrm{K}$. Above the 'ozone layer' temperature falls again with height to the cold layer, in which in the real atmosphere noctilucent clouds are seen, at about $80 \mathrm{~km}$.; the temperature at 75 and $90 \mathrm{~km}$. is $196 \cdot 86^{\circ} \mathrm{K}$. The temperature then rises again with height as we ascend through the 'ionosphere' until at $300 \mathrm{~km}$. it is taken to be $1,537 \cdot 86^{\circ} \mathrm{K}$. 'The temperatures in the 'ozone layer' are 10 deg. C. higher and those in the 'cold layer' about 10 deg. C. lower than the values adopted by the United States Rocket Panel in 1952. The specification for the levels from 20 to $32 \mathrm{~km}$. has been adopted as a United States Standard and the Committee is planning to obtain international acceptance for it. The $32-75 \mathrm{~km}$. region is termed "tentative" and the region above $75 \mathrm{~km}$. "speculative". Besides temperature, the summary table gives lapse-rate, molecular scale temperature (kinetic temperature $x$ ratio of molecular weight of air to molecular weight 